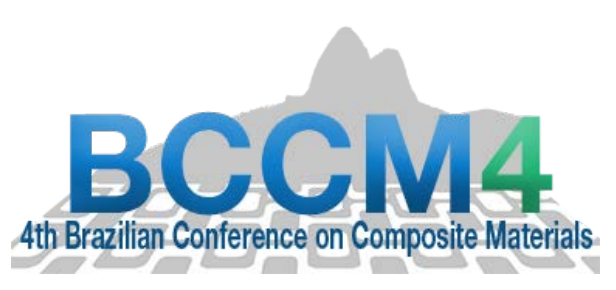

\title{
EVALUATION OF MOISTURE ABSORPTION EFFECTS ON MECHANICAL BEHAVIOR OF HYBRID GLASS/CARBON FIBERS EPOXY MATRIX COMPOSITES
}

\author{
L.M. Ottolini $^{(1)}$, J.R.M. d'Almeida ${ }^{(1)}$
}

(1) Chemical and Materials Engineering Department, Pontifical Catholic University of Rio de Janeiro, Brazil.

https://doi.org/10.21452/bccm4.2018.13.03

\begin{abstract}
This study aimed to evaluate the water absorption behavior and its effects on the Young's modulus and damping coefficient of three different types of laminated epoxy resin composites reinforced with glass and carbon fibers. The Young's modulus and the damping factor were evaluated as a function of the immersion time by a non-destructive sonic test, and their variation was correlated with the mass gain of the samples. The diffusion coefficient of water in the composites was evaluated using Fick's Law. The results showed that the water absorption increased rapidly and stabilized after 5 months of immersion. Young's modulus and damping factor values changed abruptly in the first hours of aging in water and remained constant after that. The Young's modulus decreased at first while the damping factor increased in the first hours. Plasticization of the polymer matrix seems to be the cause of the variation of these properties. The microstructure of the composites was also analyzed by both optical and scanning electron microscopy. Internal defects, such as pores and voids, were observed and their quantities affected the amount of water absorbed by each type of composite.
\end{abstract}

Keywords: Composite, moisture absorption, sonic test, mechanical behavior.

\section{INTRODUCTION}

The use of polymer matrix composites reinforced with fibers is continuously increasing over the past decades in the industry, to replace conventional engineering materials such as carbon steel. The main characteristics of these composites are high mechanical strength, chemical stability, low cost and low specific weight [1-3]. Laminated composites are the most used ones in aerospace and naval facilities as well as on many sport goods [3]. These composites present the best compromise between specific weight-mechanical resistance and resistance to crack propagation [2]. 
Under service conditions composites can be subject to damage from mechanical loading, but they are also susceptible to degradation and loss of their mechanical properties due to chemical or physical interaction with aqueous or gaseous environments [4]. The most common elements to which composites are in contact during their service lives are temperature and moisture $[4,5]$.

The moisture absorption by the polymeric matrix composites causes swelling/dilation of the polymer matrix generating cracks and microcracks in the microstructure of the material [6]. Sometimes, depending on the constituent materials of the composite, hydrolysis can occur in the interfacial region between the matrix/fiber phases. This weakens the bond strength between the matrix and the reinforcement and, consequently, reduces the mechanical resistance [4-6]. The plasticization of the polymer matrix can also occur as a function of the water absorption, which reduces the modulus of elasticity and increases the deformation of the material [4, 7].

Studies on fiberglass composites performed by Ashbee et al. [8] showed that the water diffusion led impurities into the microstructure of the material, which created small zones of high pressure and, finally lead to the appearance of internal cracks.

The kinetics of moisture absorption depends on factors such as temperature, fiber volumetric fraction, fiber affinity with water, contact surface and internal defects (pores and voids). Water absorption can occur either diffusely, according to Fick's law, or by capillarity [6, 9]. The type of absorption mechanism will depend mainly on the composite material, on the wettability of the matrix phase with the fiber, on the interfacial adhesion between matrix and fiber and the presence of internal defects [4-7].

The objective of this work was to evaluate the effect of moisture on the mechanical behavior of fiber-reinforced epoxy matrix laminated composites. To reach this goal, samples of laminated composites were immersed in tap water, simulating the environment conditions to which these materials are usually exposed during their life time. The water absorption behavior and the amount of water absorbed were correlated with the microstructure of the composites.

\section{MATERIALS AND METHODS}

Three types of epoxy matrix laminated composites plates reinforced with fiberglass and carbon fiber were analyzed. All laminates were manufactured with twelve laminas and unidirectional fibers. All the samples have the same number of layers of glass fiber and carbon fibers. The fibers were aligned parallel to the longitudinal axis of the laminate. TABLE 1 presents the dimensions, mass and lamina configuration of the samples machined from the plates.

Table 1: Characteristics of the laminated composites.

\begin{tabular}{lccccc}
\hline & \multicolumn{3}{c}{ Dimension $(\mathrm{mm})$} & Weight $(\mathrm{g})$ & Configuration \\
& Length & Width & Thickness & & \\
\hline Sample 1 & 98.15 & 25.50 & 2.05 & 9.19 & {$[1 \mathrm{G} / 2 \mathrm{C} / 6 \overline{\mathrm{G}}]_{\mathrm{s}}$} \\
Sample 2 & 103.64 & 25.52 & 2.01 & 9.59 & {$[2 \mathrm{C} / 8 \overline{\mathrm{G}}]_{\mathrm{s}}$} \\
Sample 3 & 101.64 & 25.77 & 2.15 & 10.01 & {$[4 \mathrm{G} / 4 \overline{\mathrm{C}}]_{\mathrm{s}}$} \\
\hline
\end{tabular}

$\mathrm{G}-$ Represents the layer of glass fiber.

C - Represents the layer of carbon fiber.

The samples were immersed in a glass with tap water at room temperature $\left(22^{\circ} \mathrm{C}\right)$. No type of seal was applied to the samples edges. This implies that water diffusion occurs in all directions. The glass was capped to prevent external contamination, and the total aging period was around 5 months. Samples were taken at regular intervals to measure water absorption and to evaluate the 
Young's modulus (E) and damping factor $(\zeta)$. In the first week of aging, the interval between measurements was 4 hours. After this, the interval was extended to one measurement every week and finally one measurement every three weeks. The adjustments in the intervals between measurements was necessary to avoid experimental errors due to small mass variation after a long time of aging.

The procedure for removing excess of water from the samples to mass measurement was performed in accordance to ASTM D570-98 standard. The weight of the samples was measured using a balance with an accuracy of $\pm 0.0001 \mathrm{~g}$.

The moisture absorption of the samples $\left(M_{p}\right)$ was calculated using Equation 1, where $M_{t}$ represents the mass of the laminate measured at time " $t$ " and $M_{d}$ is the initial mass of the dried laminate at $t=0$ [9]:

$$
M_{p}(\%)=\frac{M_{t}-M_{d}}{M_{d}} \times 100
$$

The experimental data adjustment was performed following Equation 2, adapted to describe the moisture absorption model in accordance to the first Fick's law, both for short and long absorption periods. In Equation 2, $M_{p}$ is the percentage moisture absorption at a given time " $t$ ", $M_{\infty}$ is the maximum moisture absorption at the saturation point, $h$ is the laminates thickness and $D$ is the diffusion coefficient [10]:

$$
\frac{M_{p}}{M_{\infty}}=\tanh \left(\frac{4}{h} \times\left(\frac{D \times t}{\pi}\right)^{\frac{1}{2}}\right)
$$

Young's modulus and damping factor were evaluated by a non-destructive sonic test. This test consists in capturing with a microphone the propagation of the sound generated by a mechanical impulse at the edge of the sample. FIGURE 1 shows the configuration of the sonic test for one sample. After the mechanical impulse, the sound is captured by an electret microphone and the signal is processed by a software incorporated into the device (Sonelastic $\left.{ }^{\circledR}\right)$. Young's modulus and damping factor values are automatically obtained from the device [11]. The calculations involved in the determination of these both parameters are based on ASTM E1878 standard. Although the sound test uses the premise that the analyzed material is homogeneous and isotropic, studies performed show that it is possible to use the technique in heterogenous materials. However, the results must be analyzed according to the boundary conditions used in the test and the geometry of the samples $[11,12]$

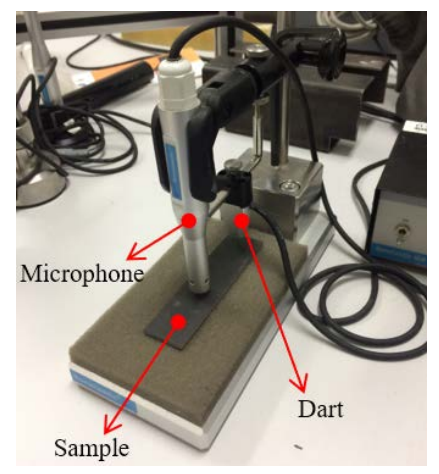

Figure 1: Apparatus for the sonic tests of the specimens 
The microstructure of the composites was analyzed by optic microscopy (OM) and scanning electron microscopy (SEM). Both methods were necessary due to the characteristics of the laminates. In the SEM, the carbon fibers do not show a sufficient contrast in relation to the epoxy matrix, because both contain carbon and, therefore, they exhibit similar average values of atomic number [13]. Thus, carbon fiber characterization was performed by OM. Fiberglass and the voids are easily detected and segmented from the images obtained by SEM. The complete characterization of the microstructures was performed from mosaics obtained in both microscopy techniques with 500x magnification. To reach the goal to determine the volumetric fractions of matrix, fibers and voids, the mosaic images were submitted to steps of preprocessing, segmentation and post processing. A FIJI software was used to quantify the volumetric fraction of the phases.

\section{EXPERIMENTAL RESULTS AND DISCUSSION}

The experimental results and the fitted curve of water absorption versus the square root of time are represented in FIGURE 2. TABLE 2 shows the values obtained from Equation 2 of the water absorption at the saturation point $\left(M_{\infty}\right)$, the diffusion coefficient (D) and the correlation coefficient of the fitted curve $\left(\mathrm{r}^{2}\right)$. It is possible to note that the experimental points adhered satisfactorily to the experimental points of the proposed Fick's law model. The correlation coefficient " $\mathrm{r}^{2}$ " ratifies this statement [14]. However, it is important to note that all composites exhibit Type I deviations of the experimental points in relation of theoretical model. Hahn [4] associates this deviation to the absorption of water molecules in two distinct phases. One phase is associated to the polymeric matrix. The water molecules are bounded to the matrix, and thus contribute to the swelling of the composite due to water absorption. The other is associated with the occupation by water molecules of the free volume, with no correlation to the composite's swelling.

Studies performed by Pritchard et al. [15] on unsaturated polyester resin laminated composites reinforced with fiberglass presented values of $1.1 \%$ and $8.1 \times 10^{-7} \mathrm{~mm}^{2} / \mathrm{s}$ for $M_{\infty}$ and $D$, respectively. The fibers of the laminate were oriented at $10^{\circ}$ and the aging temperature was $30^{\circ} \mathrm{C}$. Imaz et al. [16] found values of $1.2 \%$ and $1.04 \times 10^{-7} \mathrm{~mm}^{2} / \mathrm{s}$ for $M_{\infty}$ and $D$, respectively, in studies with epoxy resin laminated composites reinforced with carbon fibers at $20^{\circ} \mathrm{C}$. 

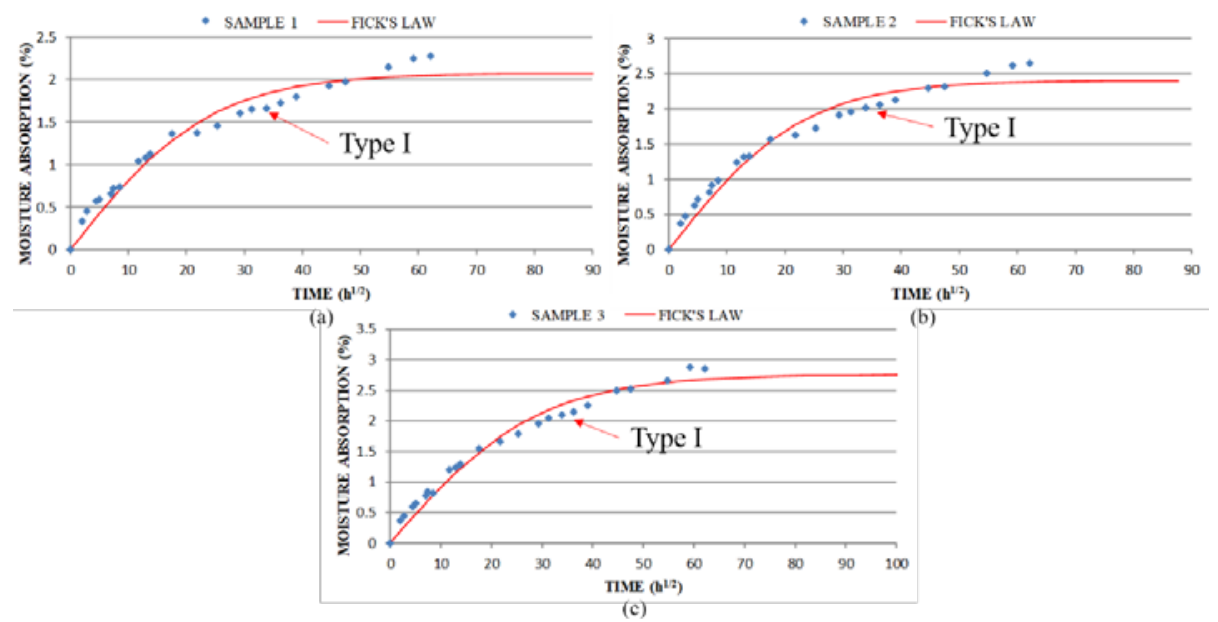

b)

Figure 2: Results of moisture absorption versus square root of aging time for samples (a) 1; (b) 2 and (c) 3.

Table 2: Water absorption parameters.

\begin{tabular}{cccc}
\hline SAMPLE & $\mathrm{M}_{\infty}(\%)$ & $\mathrm{D}\left(10^{-7} \mathrm{~mm}^{2} / \mathrm{s}\right)$ & $\mathrm{r}^{2}$ \\
\hline 1 & 2.07 & 4.33 & 0.95 \\
2 & 2.41 & 4.15 & 0.96 \\
3 & 2.75 & 2.66 & 0.97 \\
\hline
\end{tabular}

The results of the sonic test for the Young's modulus, obtained for aging times corresponding to the linear region of the graphs of FIGURE 2 and before the Type I deviation, are shown in FIGURE 3. In a comparative way, it was possible to observe that the Young's modulus of the samples 1 and 2 decrease at the first measurement after the beginning of aging. After that, the Young's modulus values remain almost constant until the end of the test. The sample 3 also shows a decrease in the Young's modulus as a function of aging time, but there was no systematic variation on the behavior. Therefore, for this sample the data are not conclusive and only shows a decreasing tendency, as seen in FIGURE 3c. 

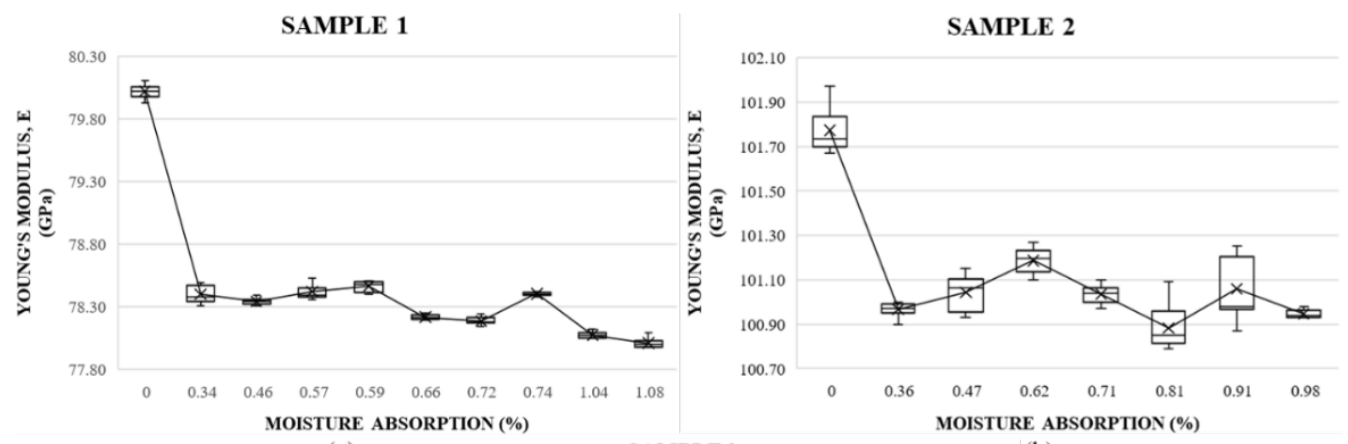

(a)

SAMPLE 3

(b)

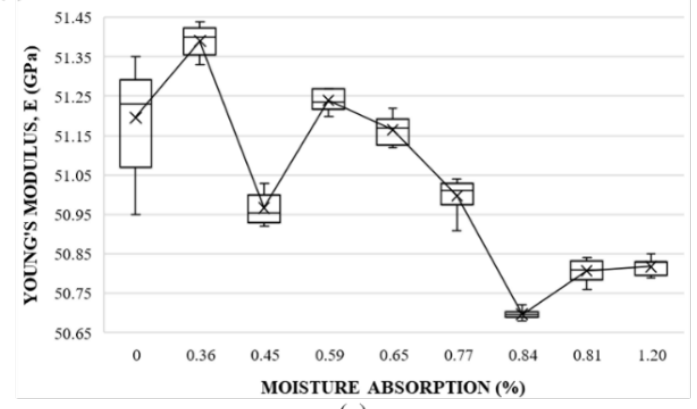

(c)

Figure 3: Results of Young's modulus of samples (a) 1; (b) 2 and (c) 3.

The damping factor of the samples are shown in FIGURE 4. It was possible to observe an increase of damping factor values for all samples in the first hours of aging time. After that, and throughout the aging period, the values tend to be constant. Again, sample 3 presented only a tendency, but without a systematic variation.

The Young's modulus and damping factor variations observed in this work are in line to those reported for a polyester-sponge gourd composite [17]. That is, both properties changed while water absorption did not reach the saturation point. The Young's modulus of polyester-sponge gourd composite decreased in the first hour of the aging while the damping factor value followed the opposite direction, increasing at the first hours of aging, as was also observed in this work. 


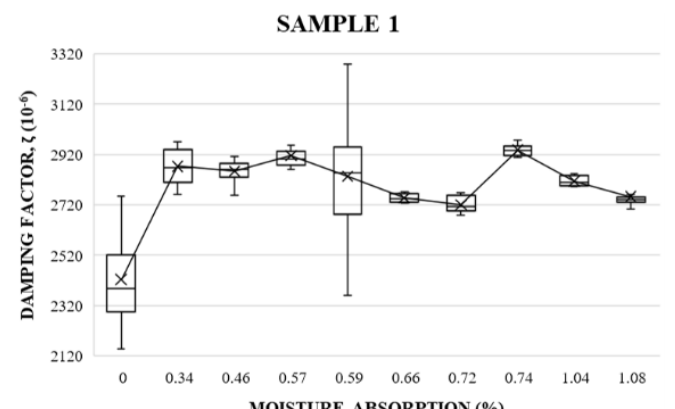

(a)

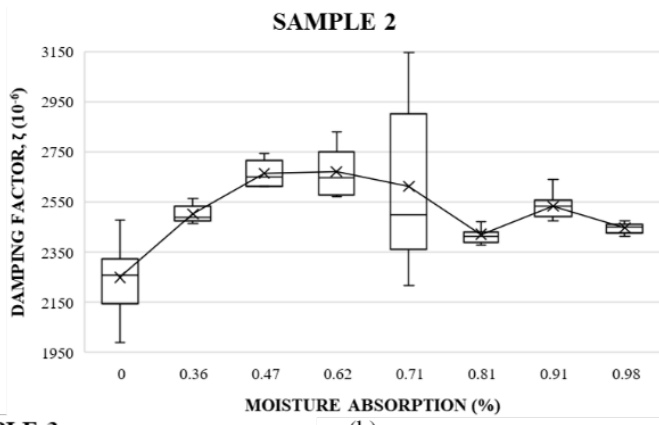

(b)

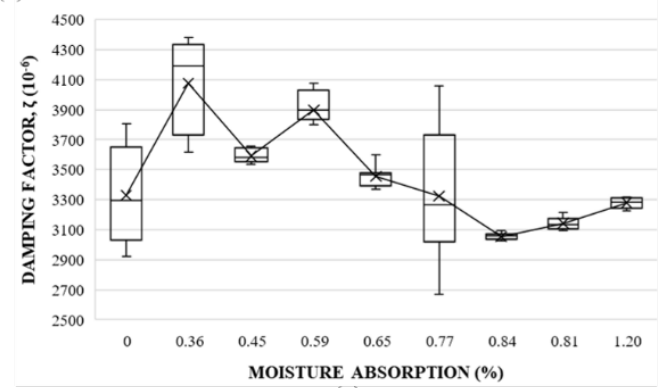

(c)

Figure 4: Results of damping factor of samples (a) 1; (b) 2 and (c) 3.

FIGURES 5 to 7 show the mosaics obtained by SEM from the cross section of the composite samples. The laminas of each sample are identified and it was possible to observe that the laminates have many internal defects (pores and voids). From the images obtained by optical microscopy, it was possible to identify that the carbon fiber layers do not have constant thickness along the width of the composite. TABLE 3 shows the values of the volumetric fractions of epoxy matrix, fibers and voids of the samples.

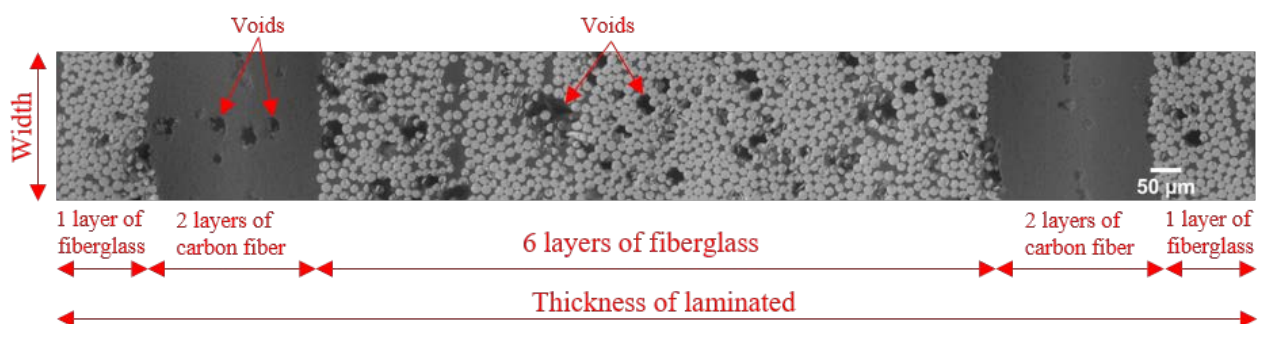

Figure 5: Image of SEM showing voids and internal defects on sample 1.

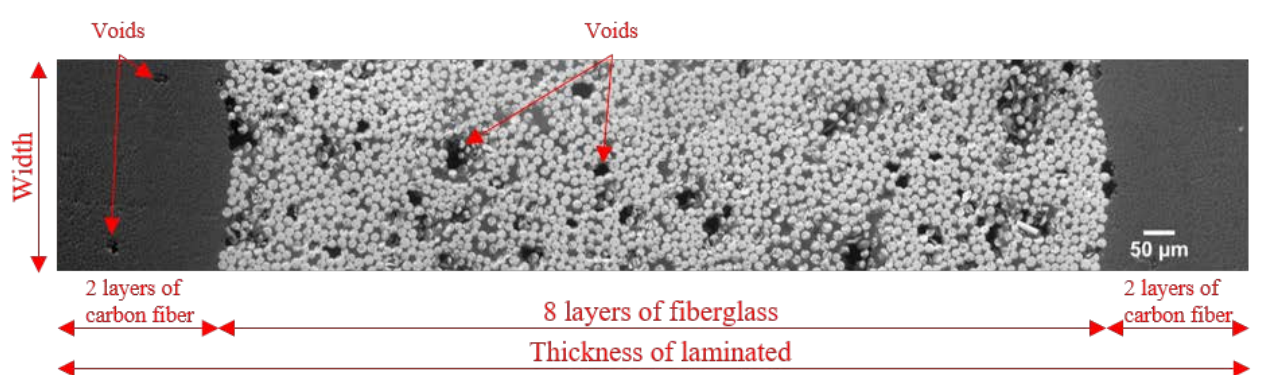

Figure 6: Image of SEM showing voids and internal defects on sample 2. 


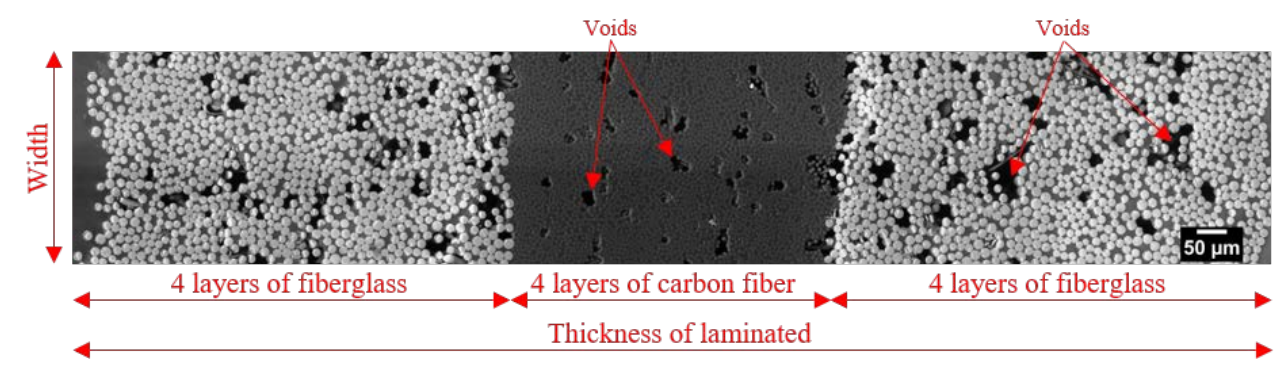

Figure 7: Image of SEM showing voids and internal defects on sample 3.

Table 3: Volume fraction of fibers, matrix and voids from SEM images.

\begin{tabular}{ccccc}
\hline SAMPLE & $\mathrm{V}_{\mathrm{m}}(\%)$ & $\mathrm{V}_{\mathrm{cf}}(\%)$ & $\mathrm{V}_{\mathrm{fg}}(\%)$ & $\mathrm{V}_{\mathrm{v}}(\%)$ \\
\hline 1 & 39.75 & 11.94 & 43.49 & 4.82 \\
2 & 45.89 & 10.45 & 40.29 & 3.38 \\
3 & 36.71 & 12.90 & 44.11 & 6.28 \\
\hline
\end{tabular}

TABLE 3 illustrates that all samples have similar volumetric fractions of fibers and resin. Thus, it is important to note that the absolute values of the Young's modulus of the samples showed in FIGURE 3 should be similar too, according to the rule of mixtures describing the behavior of composites reinforced with unidirectional fibers [1,2]. However, the results of the unaged samples showed distinct Young's modulus values. The possible reason for this behavior is associated to differences of the type of fiber placed at the top surface of the laminate, hit by the dart (FIGURE 1).

In fact, the results shown at FIGURE 3 show a decrease of Young's modulus from laminate 2 to 1 and to 3. Regarding the lamina stacking sequence for these laminates, it can be seen from TABLE 1 that composite 2 has carbon fiber placed at the outer laminas, composite 1 has once glass fiber lamina followed by one carbon fiber lamina, and composite 3 has four glass fiber laminas at their outer laminas. Thus, sample 3 should have a lower Young's modulus value than sample 2 .

It seems, therefore, that the configuration used at this non-destructive test was not able to measure the bulk response of the composite, but only the response of the outer layers. It has to be pointed out, however, that the sonic test can be used to follow the variation of the properties with time, since comparative values can be accurately measured.

\section{CONCLUSION}

From the experimental results in this work, it was possible to conclude that the moisture absorption by the laminated composites followed the Fickian model and the values of the diffusion coefficient are in line to other similar studies.

The analysis of the microstructures showed a high volumetric fraction of voids, which may be the probable cause for high water absorption of the composites at the saturation point.

The values of Young's modulus as well as the damping factor of the samples were affected by the moisture absorption, indicating that there was plasticization of the polymeric resin. The stabilization of damping factor and Young's modulus along with the aging time seems to indicate that the aging of the composites due to water absorption was mainly of the physical type. 
$4^{\text {th }}$ Brazilian Conference on Composite Materials. Rio de Janeiro, July $22^{\text {nd }}-25^{\text {th }}, 2018$

The absolutes values of the sonic test were influenced by the surface of the laminates and do not represent the properties of the bulk. Thus, the values found should be used only in a comparative way.

\section{ACKNOWLEDGEMENTS}

The authors acknowledge the support from the Brazilian Agency CNPq.

\section{REFERENCES}

[1] Chawla, K.K., 'Composite Materials’, Brd Edn (Springer Science \& Business Media, New York, 2013).

[2] Kaw, A.K., 'Mechanics of Composite Materials', 2nd Edn (Taylor \& Francis Group, New York, 2006).

[3] Mahieux, C.A., 'Environmental Degradation in Industrial Composites', 1st Edn (Elsevier Science, Oxford, 2006).

[4] Hahn, H.T., 'Hygrothermal damage in graphite/epoxy laminates', Journal of Engineering Materials and Technology. 109 (1987) 3-11.

[5] Ray, B.C., 'Temperature effect during humid ageing on interfaces of glass and carbon fibers reinforced epoxy composites', Journal of Colloid and Interface Science. 298 (2006) 111-117.

[6] Costa, M.L., Rezende, M.C. and Almeida, S.F.M., 'Effect of void content on the moisture absorption in polymeric composites', Polymer-Plastics Technology and Engineering. 45 (2006) 691-698.

[7] d'Almeida, J.R.M., Almeida, R.C. and Lima, W.R., 'Effect of water absorption of the mechanical behavior of fiberglass pipes used for offshore service waters', Composite Structures. 83 (2008) 221225.

[8] Ashbee, K.H.G. and Wyatt, R.C., 'Water damage in glass fibre/resin composites', Proc. Roy. Soc. A. 312 (1969) 553-564.

[9] Shen, C.H. and Springer, G.S., 'Moisture absorption and desorption of composites materials', Journal of Composite Materials. 10 (1976) 2-20.

[10] McKague, Jr.E.L., Reynolds, J.D. and Halkias, J.E., 'Moisture diffusion in fiber reinforced plastics', Journal of Engineering Materials and Technology. 98 (1) (1976) 92-95

[11] Otani, L.B. and Pereira, A.H.A., 'Caracterização dos módulos elásticos de compósitos utilizando a técnica de excitação por impulso’, Informativo Técnico-Científico ITC-06/ATCP. (2014).

[12] Otani, L.B., Pereira, A.H.A., Segundinho, P.G.A and Morales, E.A.M., 'Caracterização dos módulos elásticos de madeiras e derivados utilizando a técnica de excitação por impulso', Informativo TécnicoCientífico ITC-05/ATCP. (2015).

[13] Goldstein, J.I, Newbury, D.E., Echlin, P., Joy, D.C., Fiori, C. and Lifshin, E., 'Scanning Electron Microscopy and X-Ray Microanalysis', 1st Edn (Plenum Press, New York, 1981).

[14] Devore, J. L., 'Probabilidade e Estatística para engenharia e ciências', 2nd Edn (Cengage Learning, São Paulo, 2014).

[15] Pritchard, G. and Speake, S.D., 'The use of water absorption kinetic data to predict laminate property changes', Composites. 18 (3) (1987) 227-232.

[16] Imaz, J.J., Rodriguez, J.L., Rubio, A. and Mondragon, I., 'Hydrothermal environment influence on water diffusion and mechanical behavior of carbon fibre/epoxy laminates', Journal of Materials Science Letters. 10 (1991) 662-665.

[17]Feiferis, S. and d'Almeida, J.R.M., 'Evaluation of water absorption effects on the mechanical properties and sound propagation behavior of polyester matrix-sponge gourd reinforced composite', Journal of Composites and Biodegradable Polymers. 4 (2016) 26-31. 